\title{
A Review on Multiple Survey Report of Cloud Adoption and its Major Barriers in the Perspective of Bangladesh
}

\author{
Md. Masudul Islam \\ Bangladesh University of Business and Technology (BUBT), Dhaka, Bangladesh \\ E-mail: masudulislam11@gmail.com \\ Mijanur Rahaman \\ Bangladesh University of Business and Technology (BUBT), Dhaka, Bangladesh \\ E-mail: riponcse.it@bubt.edu.bd
}

\begin{abstract}
Cloud computing is called globalization for computer and internet. Either directly or indirectly we are using cloud technology almost every day. Today cloud computing is getting popular in every developed country, but it's not over all officially adopted in most of the 3rd world developing country like Bangladesh. This paper will show some categorize survey of continuous progress, advantages, disadvantages, dependencies, maturity of cloud computing from 2012 to till now. Also we will show recent ranking of cloud adoption in different country. Also our main target will review major barriers to adopt cloud. Finally we will propose some initial steps to adopt cloud technology in our country by studying previous trade-off factors of survey report.
\end{abstract}

Index Terms - Cloud computing, cloud barrier, cloud survey, 3rd world country, cloud adoption, Bangladesh.

\section{INTRODUCTION}

Now a days cloud computing has become a buzzword all over the world. According to NIST, Cloud Computing is a model for enabling ubiquitous, convenient, ondemand network access to a shared pool of configurable computing resources that can be rapidly provisioned and released with minimal management effort or service provider interaction. ${ }^{[1]}$ We have already flavored of cloud computing in our day to day life, for example, Email sending or Google Drive, Drop Box document hosting etc so that we can access our document from anywhere without having own local storage. Cloud computing are managed by Cloud Management tools, loaded and tested by various other software testing tools. Cloud computing modelling and simulation is done by CloudSim or SPECI or GroundSim or DCSim on the basis of testing benchmark. [15] But to establish this system there are some interoperability challenges. Many of these challenges are in relation with technological tools, which are employed for implementation for services, and other challenges are related to technical aspects and maybe related to management decisions. So, to implement this system in better state we need to propose solutions for these challenges. In overall, these challenges fall into three types, different Hypervisors, platforms and policies in cloud managements. [16] In our paper we concentrate highly on giving a brief review on different categories of survey from different times and various reports on cloud adaptation status in the world information system and provide a summery view of why cloud adaptation in third world country like Bangladesh is still not getting well progressed. This paper will illustrate what we should concern mostly to established cloud system in our country Bangladesh according to these survey reports. Finally there are given some initial steps to make easy the cloud computing to entrepreneur in our developing country.

To understand briefly and easily there are 5 essential characteristics, 4 common deployment models and 7 services models in Cloud Computing:

\section{A. Characteristics}

On-demand self-services; which provides automatic system capabilities to server user. Measured services; where both user and provider can monitor their resources usages. Resources sharing; where provider's computers are united to serve multiple users at a time. Broad network access; where user can access any services and resources from anywhere in network. Rapid Elasticity; where consumer can access any information rapidly and freely.

\section{B. Deployment}

Public cloud; which is controlled by only one person and open for public use, for example; Microsoft Azure, Google Cloud etc. Community cloud; where groups of same type organization setup their cloud to share their information. Private cloud; which is completely used by single organization and can be maintained by third party. Hybrid cloud; which is the mixture of two of more public, private cloud system.

\section{Service Model}

Cloud computing provides different service models 
such as, SaaS (Software as a Service), IaaS (Infrastructures as a Service), PaaS (Platform as a Service), DaaS (Data as a Service), NaaS (Network as a Service), StaaS (Storage as a Service)

\section{Major Advantages}

There are some benevolent facts of cloud computing. Such as, there is no need of high configuration PC for extreme type of works such as animation, graphics, powerful software access etc. No delaying on extra software of file loading in local PC. No need to purchases basic software packages in cloud system. No limitation of power usage when we are accessing cloud because server provides us best configuration where local computer has a limited storage. No need to worry about regular updated software. Server automatically update by itself. No need to worry about storage crash or data loss. We can access our data from anywhere at any place in network from cloud. If the cloud system model has a grid computing back-end then user can research or analyze big complex data using the whole system as a super computer.

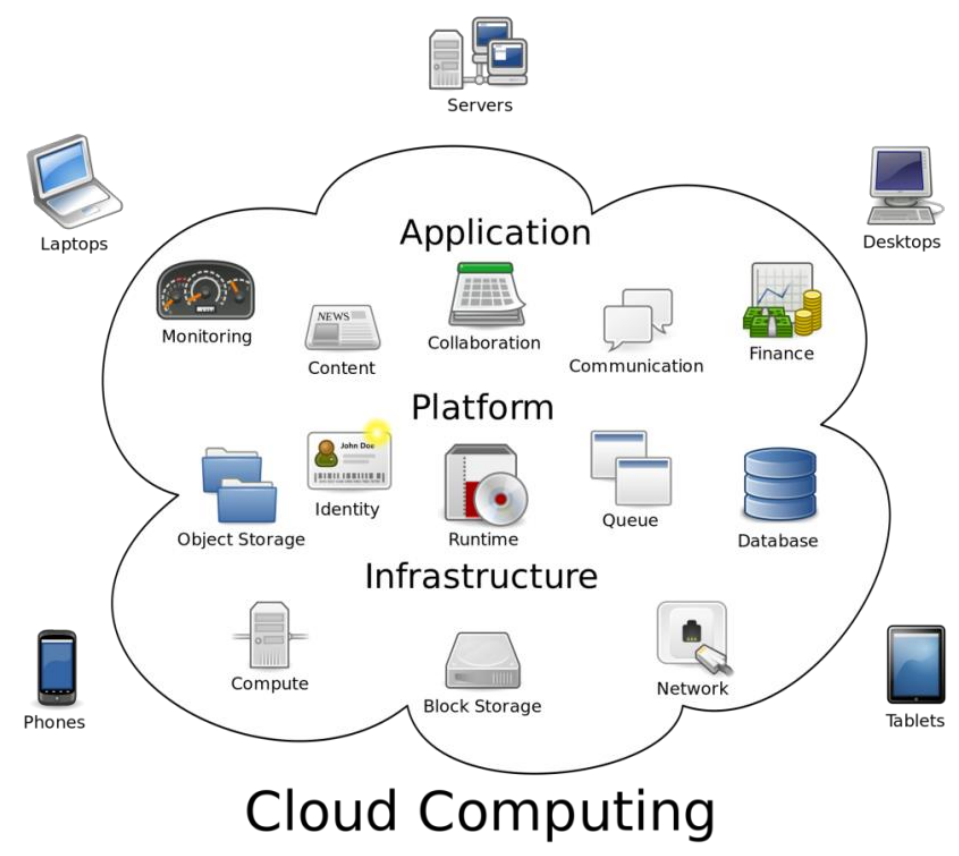

Fig.1. Cloud System Architecture [2]

\section{DEPENDENCIES \& WEAKNESS OF CLOUD}

Although cloud computing system has advantages, but there are major dependencies which make some weakness for cloud system, they are:

1. Internet compatible devices- it's may not very weak point for cloud system but still $3^{\text {rd }}$ world countries has not much ability to available one.

2. Internet connection- most important fact for cloud. It's completely impossible to use cloud system without internet connection. No matter how much good device you have without internet cloud system is nothing.

3. Low speed internet- many software services doesn't successfully run in low speed internet connection.

4. Security \& privacy- Most important fact in cloud system. No matter how carefully we store our precious data with secure encryption in cloud, there will always be a third party service provider who has the fundamental access of those data at any time.
Beside these there are some important unaware fallacies about cloud computing in business level. We think cloud is always free but in reality is the more data storage we need in server the more we have to pay for per unit of time. So the question comes, "Why more money wasting for cloud?" Also Cloud basically combination of network and cloud service provider. So there are different charges for each service. Also consumers are bounded to add overall cost without prediction how much services they will need in far future. When "Cloud Computing" comes to our mind we think the whole system is free to access, globalized and universally compatible. But truth is different cloud are different in nature and one may not be working with all of them. For example; someone using Google Docs cloud may not be integrated with another cloud QuickBooks online. Most of our favorite software or customized application software in local PC may not be in cloud version. So, inter cloud integration is still a problem. 


\section{MUlTiPle SURVEY REVIEW}

From 2009 till now many organization has done survey on cloud computing from different aspects. These are the vital points for cloud adoption in developing country like
Bangladesh. Based on these survey reports we will ensure how much progress has done and should do in our present situation. According to BSA Global Cloud Computing Scorecard 2012, 24 countries from different continent have ranked in successful cloud adoption. [3]

\section{Cloud Computing Ranking by Country-wise}

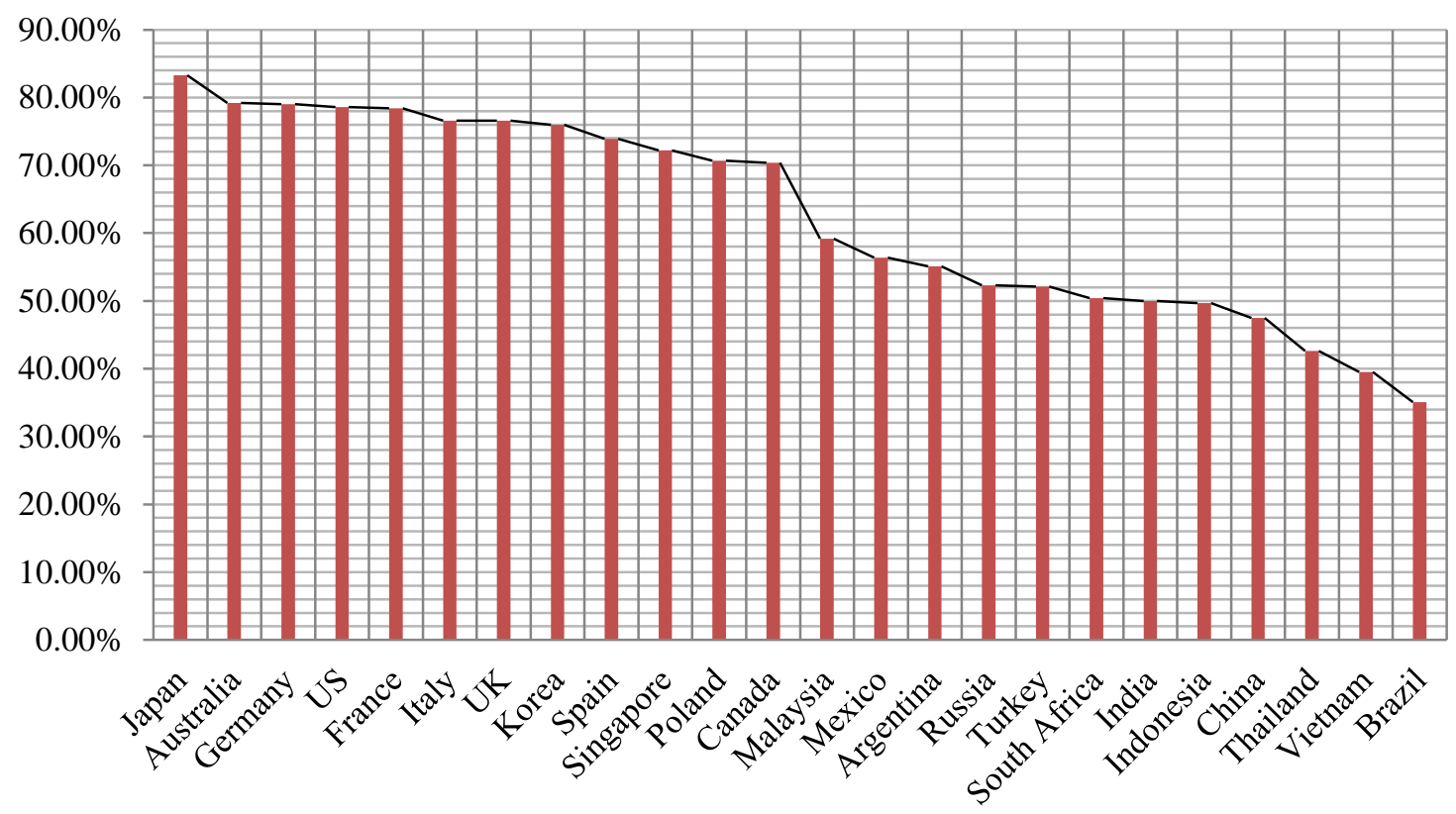

- SCORE

Fig.2. Country-wise Cloud Computing Ranking in 2012

If we simplified the ranking according to first-secondthird world country wise then we will see that a very few number of 3rd world country has adopt the cloud system.

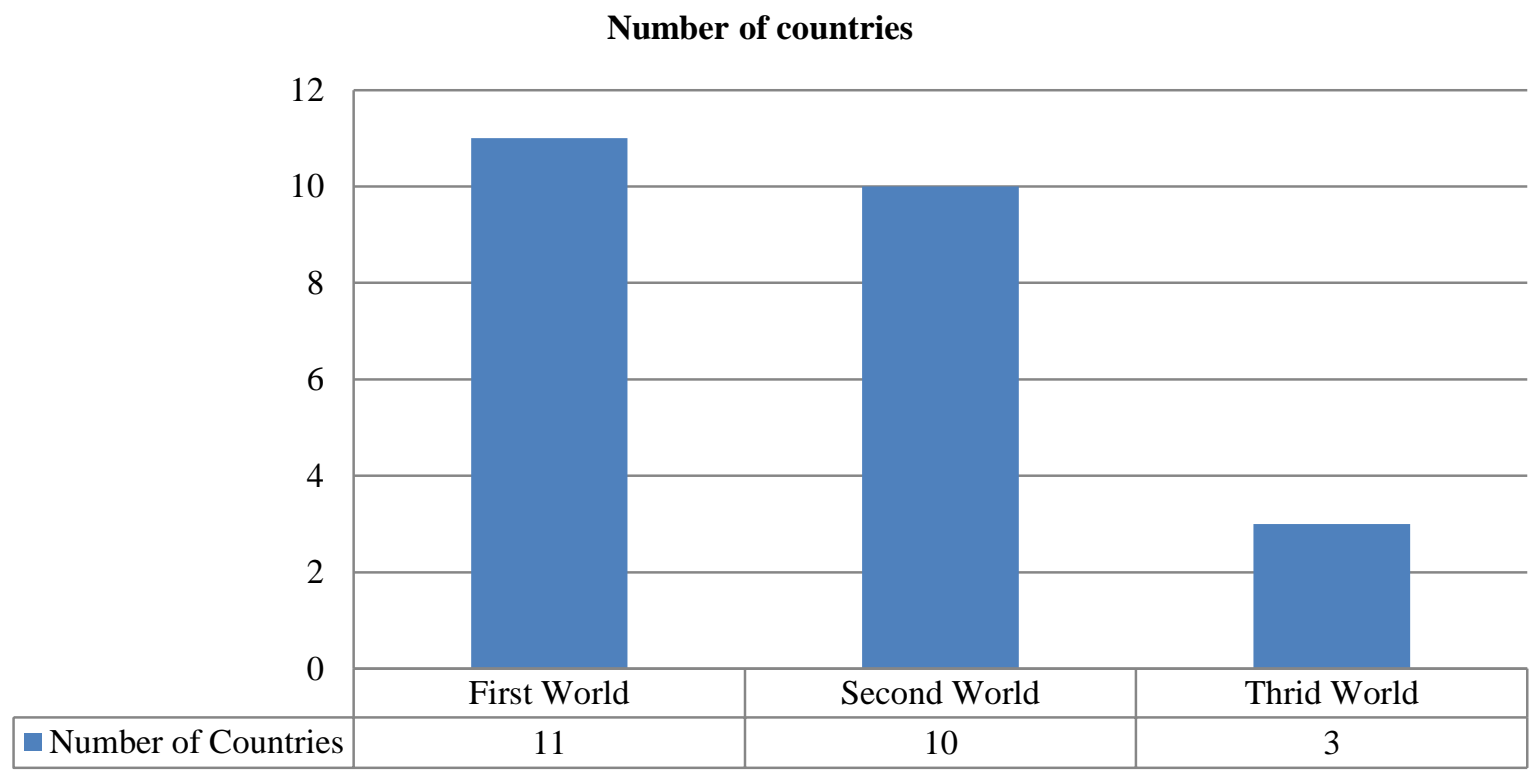

Fig.3. Country Categories in Cloud Adaptation

As per Techsoup Global Network survey in 2012 over 10,500 non-profit organizations [4] which illustrated a timeframe for moving a significant portion of IT to the Cloud: 


\section{Opinion of organizations to move a significant portion of their system in Cloud}

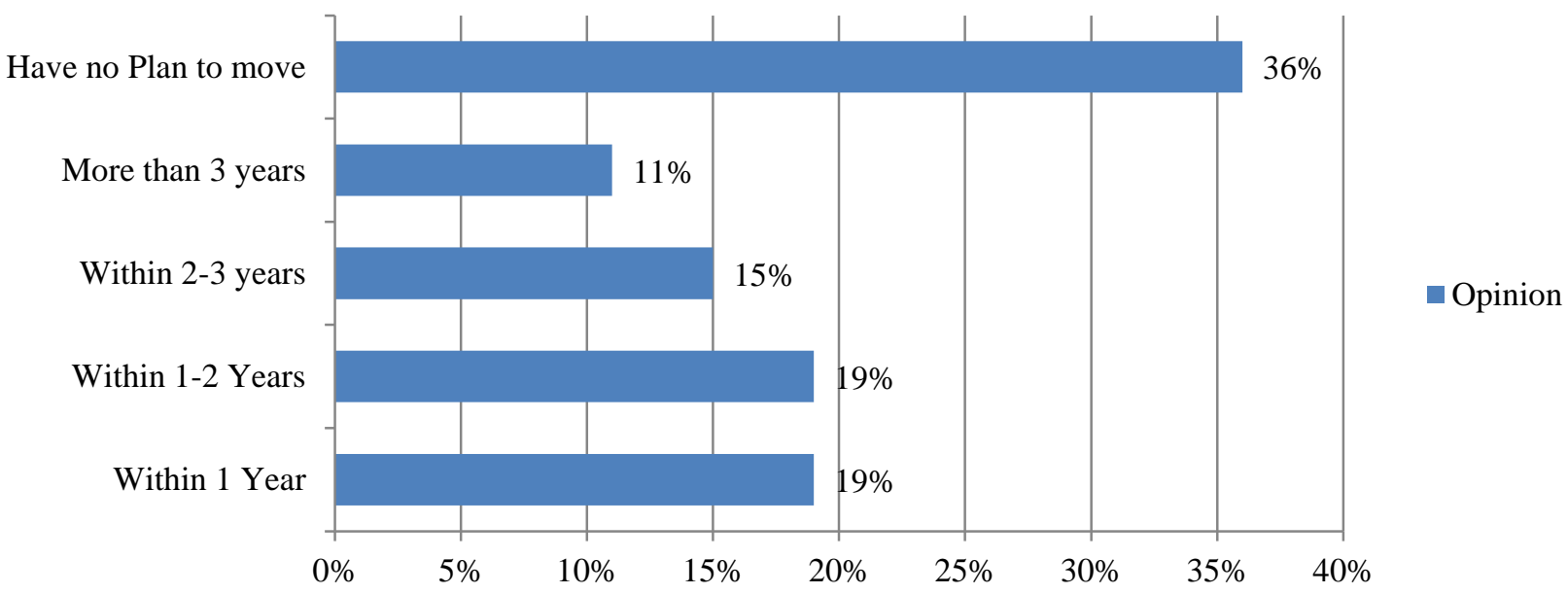

Fig.4. Organizations' Opinion to Move a Significant Portion of Their System in Cloud

Based on Right Scale survey on the state of the cloud in 2014 on 1068 technical professionals from different organizations and another survey in 2015 on 930 IT professionals on cloud maturity of respondents shows some major fluctuations: [5][6]

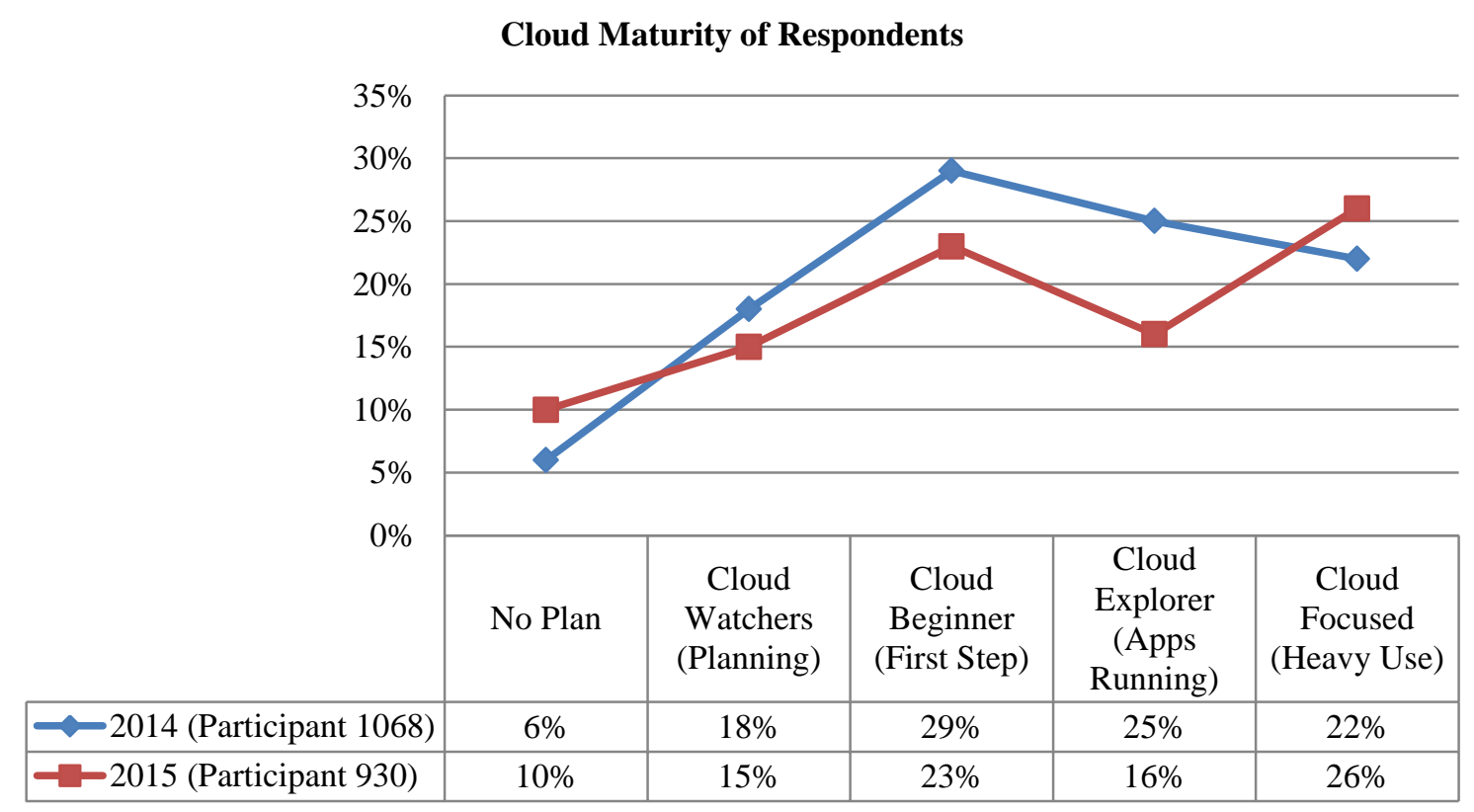

Fig.5. Cloud Maturity

If we analyze Fig: 5 data we will see overall respondents of cloud adoption planning and usage is slightly downgraded. Most of the organizations, entrepreneur, IT professionals aren't yet totally involving into cloud system, especially in developing country. Because there are some major barriers to adopt the cloud computing. We are presenting 6 different cloud computing survey in a comparison chart from timeline 2012 to 2015 in Fig: 6. According to Techsoup Global Network survey in September 2012 [7], KPMG cloud survey report 2014 [8], RightScale cloud survey in 2014
[9], Harvard Business Review survey report on 376 business \& technology leaders "Cloud computing comes of age" published in 2015 [10], another survey held by Mircosoft Technet published in 2015 [11] on 1,979 IT professionals' and RightScale cloud survey in 2015 [12] shows some same categories of barriers to adopt the cloud computing system. In here Non-controllable Externalities are burning question for most countries. The major Non-controllable Externalities are: Government regulations, Unstable Electricity facility, Lack of dependable internet connectivity, foreign currency. 
Barriers

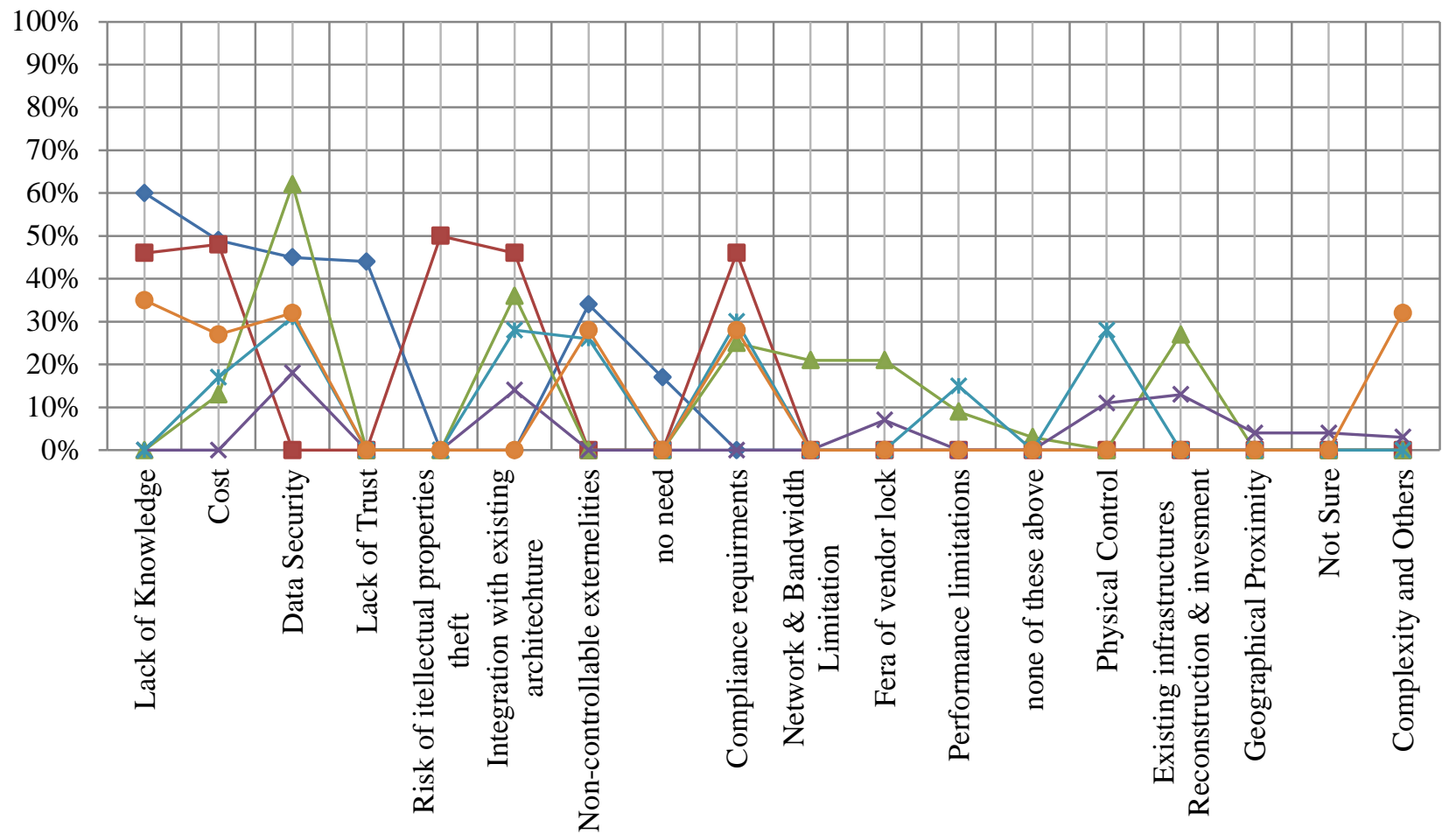

$\multimap$ Techsoup Global Network Survey $2012 \multimap$ KPMG cloud survey report 2014

- Harvard Business Review 2015

$\leftarrow$ Mircosoft Technet Cloud Survey 2015

$\rightarrow$ - Right Scale 2014 Cloud Survey

\section{- Right Scale 2015 Cloud Survey}

Fig.6. Major Barriers to Adopt Cloud System

So basically within 2012 to 2015 from different aspects of survey in adoption of cloud system the barrier is almost same.

\section{Cloud AdOPTION IN BANGLADESH}

According to the political designation 3rd world country principally consists of the developing world, former colonies of Africa, Asia and Latin America. [13] Despite ever evolving definitions, the concept of the third world serves to identify countries that suffer from high infant mortality, low economic development, high levels of poverty, low utilization of natural resources, and heavy dependence on industrialized nations.[14] So mostly Bangladesh is a developing country. It has not much improved in power grid system, wide and super speed internet connectivity, smart device availability and financially self-dependency. According to 2012-2013 world economic forum's competitive report shows that Bangladesh is still a poor in economic structures because of poor digitalization infrastructure. In the case of cloud adaptation it looks like the whole system is work as center of gravity. To established this system we have to implement part by part plan such as; raise education, IT consciousness, connectivity, government support, private sector's involvement, innovative idea and huge device infrastructure. But there are still not much organization, IT professionals, business company are showing their interest in cloud computing. They are satisfied in their old system \& technology. Lack of government involvement, not have much clear idea about cloud computing and afraid of being involved in new technology are also major problem in cloud adoption.

To gain successful cloud adoption BTRC (Bangladesh Telecommunication Regulatory Commission) should provide better bandwidth to the cellular telephone service operator, then those operators could frequently provide the end user (the person who has smart technology) the cloud related services. Government can easily offer cloud system to any user with proper protocol. Also various organization and institutes can hold regular cloud conference, summit, work shop etc. to advertise and address the cloud computing to new IT professionals and entrepreneur.

\section{CONCLUSIONS}

In this paper we try to show through some survey report the different level of cloud computing around the world, its advantages, its major disadvantages, our typical concerns about the cloud system, some major barrier to adopt cloud system widely in third world country like 
Bangladesh. By this review we can take proper step to minimize the barrier and analyze to provide more beneficiary cloud system to the end user.

\section{REFERENCES}

[1] Peter Mell, Timothy Grance, "The NIST Definition of Cloud Computing" The NIST Definition of Cloud Computing. NIST Special Publication 800-145, U.S Department of Commerce. September, 2011. Text.

[2] Johnston, Sam. Cloud computing. 2009. Wikipedia. Web. 17 August, 2015.

[3] "Country Ranking." Global Cloud Computing Scorecard, Business Software Alliance. 2012. Web. 17 August, 2015.

[4] Techsoup.Org. 2012 Global Cloud Computing Survey Results. Techsoup Global Network, 2012.

[5] RightScale. 2014 State of the Cloud Report. RightScale. Print.

[6] RightScale. 2015 State of the Cloud Report. RightScale. Print.

[7] Techsoup.Org. 2012 Global Cloud Computing Survey Results. TechSoup Global Network, 2012.

[8] KPMG. 2014 Cloud Survey Report. KPMG Global Network, 2014.

[9] RightScale. 2014 State of the Cloud Report. RightScale. Print.

[10] Harvard Business Review. Cloud Computing Comes Of Age. Harvard Business School Publishing, 2015. Print.

[11] Microsoft. Cloud Computing Survey the Result. Microsoft Technet, 2015.

[12] RightScale. 2015 State of the Cloud Report. RightScale. Print.

[13] "Third World." Merriam-Webster's Collegiate Encyclopedia. Merriam-Webster Inc, 2000. 1610. Print.

[14] "First, Second and Third World." One World Nations
Online. nationsonline.org, 1998. Web. 17 August, 2015.

[15] Md. Imran Alam, Manjusha Pandey, Siddharth S Rautaray, "A Comprehensive Survey on Cloud Computing" IJITCS, Vol. 7, No. 2, January, 2015.

[16] Bahman Rashidi, Mohsen Sharifi, Talieh Jafari,"A Survey on Interoperability in the Cloud Computing Environments", IJMECS, vol.5, no.6, pp.17-23, 2013.DOI: 10.5815/ijmecs.2013.06.03.

\section{Authors' Profiles}

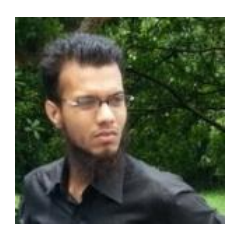

Md. Masudul Islam, Lecturer in Dept. of CSE in Bangladesh University of Business \& Technology. He has developed an entire online student management system for Bangladesh University of Business and Technology. He was the webmaster in ACMICPC 2014 regional contest. He has developed a full-featured online automation system for ACM-ICPC regional Dhaka site contest. His main areas of working are Web technologies, quantum physics \& computing and cloud computing.

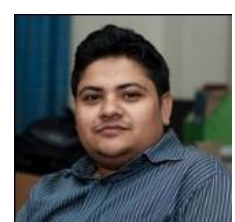

Mijanur Rahaman, Lecturer in Dept. of CSE in Bangladesh University of Business $\&$ Technology. His main area of working is networking, cryptographic security system and software base automation system. He is the developer and controller "Student Information and Management System" software of current university. He was the main webmaster and master analyzer of ACM-ICPC regional Dhaka site 2014.

How to cite this paper: Md. Masudul Islam, Mijanur Rahaman,"A Review on Multiple Survey Report of Cloud Adoption and its Major Barriers in the Perspective of Bangladesh", International Journal of Computer Network and Information Security(IJCNIS), Vol.8, No.5, pp.42-47, 2016.DOI: 10.5815/ijcnis.2016.05.06 